\title{
Correction of the combustion engine run irregularity in hybrid systems
}

\author{
Antoni Iskra, Prof. \\ Poznan University of Technology
}

\begin{abstract}

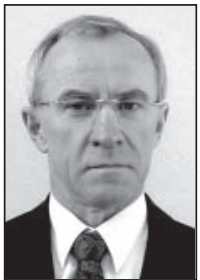

Possibilities of combustion engine-electric machine assembly run irregularity improvement have been presented in the following paper. Such system is the basic one in numerous hybrid car available on the market but the concept of using an electrical machine for reduction of rotational speed changeability amplitude in reciprocating machines could be utilized in any drive unit, especially in ship propulsion. This idea consists in generation of braking torque by the electric machine whenever the coupling shaft increases its rotational speed and vice versa, driving the system when the momentary speed is lower than the average speed within a complete shaft rotation.
\end{abstract}

Keywords: hybrid drive, run irregularity

\section{INTRODUCTION}

From the very beginning of its history an internal combustion engine which is one of the most important inventions initializing technical civilization created problems resulting from the changeability of torque transferred to the power receiver. Contrary to electric motors or turbines cyclicity of thermodynamic changes which cause the cyclicity of generated torque is the essence of reciprocating machine operation. However, there is no thermal machine as efficient as the piston engine in ener gy transformation from chemical to mechanical one. A question arises whether the basic disadvantage of reciprocating engine consisting in changeability of instantaneous speed within a single cycle could be eliminated. A flywheel, invention known from the very beginning of engine history serves as the device moderating the speed irregularity. Certainly, an increase in cylinder number contributes to the speed equalization as well. Unfortunately both solutions used in almost every combustion engine bring about specific drawbacks. The flywheel increases weight of engine and vehicle as well. As a matter of fact a similar ef fect can be achieved by the increase in flywheel overall dimensions but hardly ever engine dimensions are defined by the flywheelAs the result dimensions and moment of inertia are the compromise of the possibly lowest speed irregularity and engine weight and dimensions. Without going into details one can assume that for a defined engine swept volume an increase in cylinder number leads to the deterioration of mechanical efficiency and to an increased specific fuel consumption as well. Other group of problems connecting with the subject of engine run irregularity are the torsional vibrations within the range of unit natural frequencies. Following the development of combustion engines one can notice that the problems of resonance vibrations were the prime mover of the research on limitation of instantaneous speed change amplitude. Insufficient recognition of resonance vibration problem usually ends in a user dangerous failure consisting in the shaft breakup. The only solution that allow to avoid hazards is the use of torsional vibration dampers. Unfortunately, damping means energy dissipation and unavoidable increase in fuel specific consumption.

So what can be done to avoid the above mentioned disadvantages of solutions aimed at improvement of engine run irregularity?

The answer could be an application of hybrid drive to automobiles. There are forecasts that in a near future a considerable number of cars will be equipped with an arrangement facilitating the recovery of enegy during braking and then using it to accelerate the carHowever, the concept of application of electrical machine to the reduction in rotational velocity of reciprocating machines could be utilized in any drive unit including ship propulsion in particular Such arrangement requires use of a set consisting of:

generator that can operate as electrical motor,

- converter modifying the generated current to battery,

- suitable batteries.

In order to use the arrangement reasonably its power should correspond to the power of combustion engine, at least it should not be less than $10 \%$ of engine nominal power. 
Tab. 1. Parameters of electrical energy accumulators where energy is freed as a result of reversible chemical reactions

\begin{tabular}{|c|c|c|c|c|c|}
\hline \multirow[b]{2}{*}{ Battery type } & \multirow[b]{2}{*}{$\begin{array}{c}\text { Energy } \\
\text { concentration }\end{array}$} & \multirow[b]{2}{*}{$\begin{array}{c}\text { Power } \\
\text { concentration }\end{array}$} & \multicolumn{2}{|c|}{ Life span } & \multirow[b]{2}{*}{$\begin{array}{c}\text { Cost of energy } \\
\text { concentration } \\
\text { unit }\end{array}$} \\
\hline & & & $\begin{array}{c}\text { Number of charge } \\
\text { cycles }\end{array}$ & $\begin{array}{l}\text { Time of energy } \\
\text { and power } \\
\text { preservation } k\end{array}$ & \\
\hline & kWh/kg & kW/kg & - & years & zl per kWh \\
\hline Lead & $0.03-0.04$ & $0.2-0.3$ & $300-400$ & $2-3$ & $400-600$ \\
\hline Nickel-Cadmium & $0.04-0.05$ & $0.080-0.180$ & $\left.>2000^{1}\right)$ & $3-10$ & 2500 \\
\hline $\begin{array}{l}\text { Nickel-Metal } \\
\text { Hydride } \\
(\mathrm{Ni}-\mathrm{MH})\end{array}$ & $0.06-0.15$ & $0.20-0.30$ & $>1000$ & 10 & 1200 \\
\hline $\begin{array}{c}\text { Sodium-Nickel- } \\
\text { Chloride } \\
(\mathrm{NaNiCl})\end{array}$ & $0.09-0.10$ & 0.16 & 1000 & $5-10$ & 1000 \\
\hline $\begin{array}{l}\text { Lithium-Ion } \\
\text { (Li-Ion) }\end{array}$ & $0.09-0.14$ & $0.30-0.60$ & $500-750$ & 4 & $1000-2000$ \\
\hline $\begin{array}{l}\text { Lithium-Polymer } \\
\text { (Li-Po) }\end{array}$ & $0.11-0.13$ & 0.30 & 500 & Data unavailable & 1000 \\
\hline Zinc-Air & $0.10-0.22$ & 0.10 & Data unavailable & Data unavailable & 250 \\
\hline Capacitor & 0.005 & $1-5$ & 500000 & 10 & Very high \\
\hline Target values & 0.20 & 0.50 & 1000 & 10 & 100 \\
\hline Gasoline tank & $\begin{array}{c}8.5 \\
\text { or about } \\
\left.2^{2}\right)\end{array}$ & $\begin{array}{c}1 \\
\text { limited by engine } \\
\text { power }\end{array}$ & No limits & $\begin{array}{l}\text { Practically no } \\
\text { limits }\end{array}$ & $\begin{array}{c}2 \\
\text { or about } \\
\left.10^{2}\right)\end{array}$ \\
\hline
\end{tabular}

$\left.{ }^{1}\right)$ on condition that user prevents so called memory effect caused by charging battery not fully discharged;

${ }^{2}$ ) converted to the mechanical energy unit, which results from assumed efficiency of IC engine of about $25 \%$

Amount of energy gathered cyclically in battery is not great. A simple calculation proves that amount of enegy required for acceleration of a passenger car is far lower than that contained in start battery, i.e. about $1 \mathrm{kWh}$. As it turns out, so called energy concentration of known batteries is a crucial limitation. A classic lead battery of $100 \mathrm{Ah}$ capacity and $12 \mathrm{~V}$ voltage can give back energy with satisfactory efficiency with power not exceeding $1 \mathrm{~kW}$. So the use of batteries of higher capacitye.g. $1000 \mathrm{Ah}$ becomes a necessity in the hybrid arrangements. On that score a good solution is the use of high enegy capacitors. High power concentration and low ener gy concentration are their properties. Table 1 presents basic properties of electrical energy accumulators, including high energy capacitors $[1,2]$.

The idea of hereby study is an evaluation of possibilities to make use of car hybrid drive in order to improve the engine run irregularity. In the case of ship propulsion the control of torque variability of the auxiliary electrical machine coupled to the piston engine of main propulsion in order to remove the rotational speed variable component is far easier thanks to the lower frequency of this component in comparison to the automobile drives.

\section{AN INSTANTANEOUS POWER OF IC ENGINE}

A piston combustion engine generates momentary power far higher than the average one, i.e. power given by producer as nominal power. In principle, by the increase in cylinder number of an in-line engine one can achieve the mean power close to the instantaneous maximum power. Such direction of modifications leads to the improvement in the $\delta$ engine run irregularityAlas, contrary situations also happen. Fig. 1 presents a course of torque momentary value generated by a 4-cylinder engine, while Fig. 2 presents the same for a 5-cylinder engine.

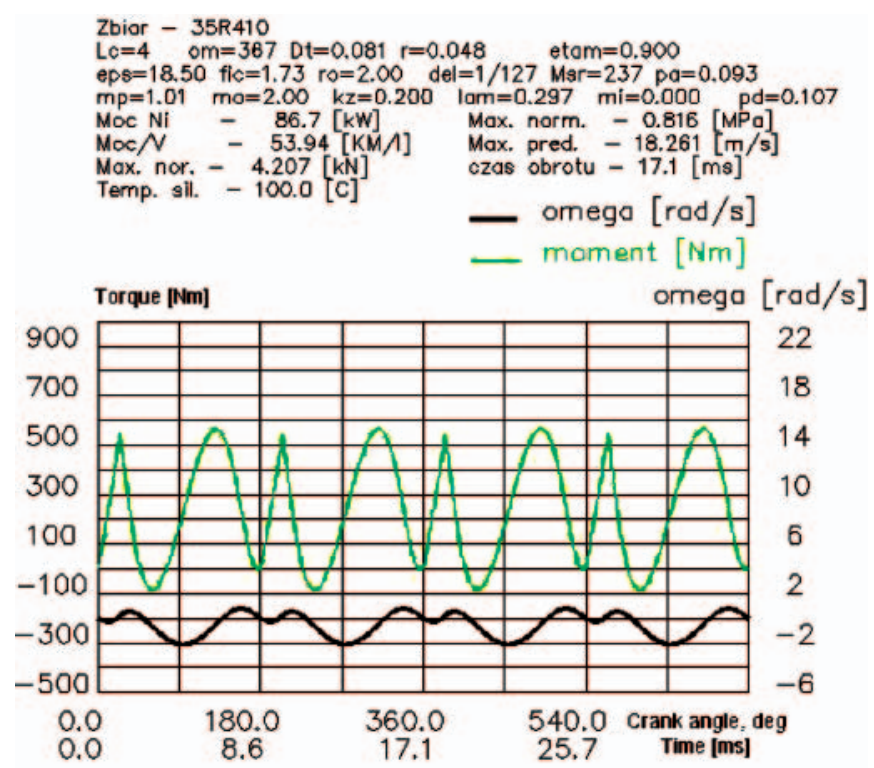

Fig. 1. Course of torque generated by an in-line 4-cylinder engine-green line and the course of speed produced by this torque

The run irregularity level $\delta$ marked as "del" and the mean indicated torque marked as "Msr" can be found above charts in $3^{\text {rd }}$ row. The relation of torque maximum value to its mean value is 2.4 for a 4 -cylinder engine and 3.5 - for the 5-cylinder one. 


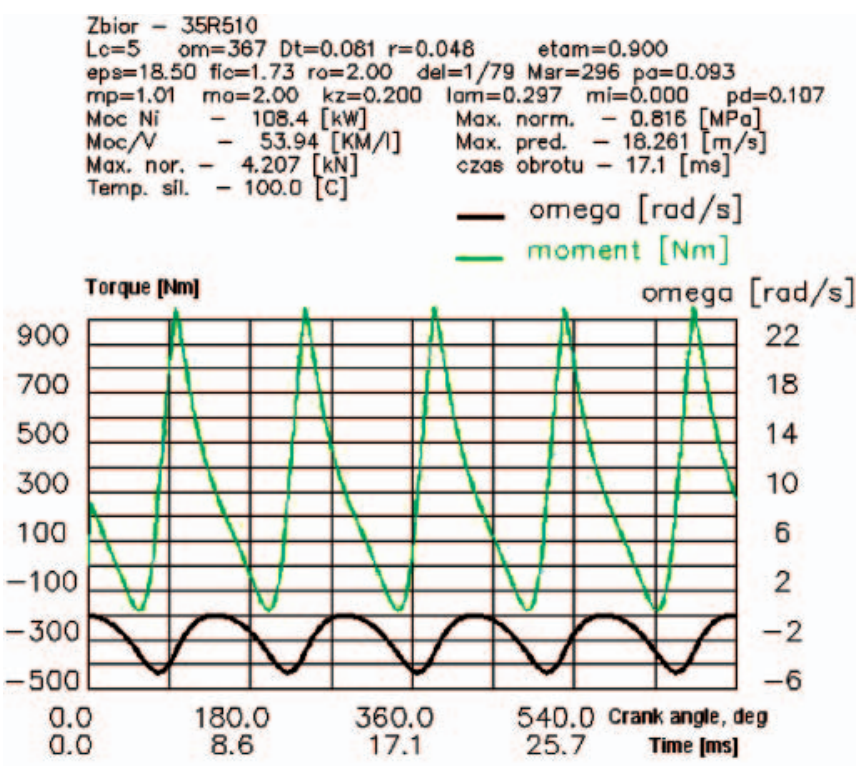

Fig. 2. Course of torque generated by an in-line 5-cylinder engine-green line and the course of speed produced by this torque

Presented examples show complexity of conditions affecting torque transmitted to the power receiver . Unfortunately, changeability of torque brings about negative results in form of vibrations which significantly increase the stress in power drive, i.e. in couplings, joints, gears and so onThese phenomena have been known for years.A counteraction consists in definition of vibration amplitude at resonance caused by a certain harmonics of torque and eventual check if admissible stress has not been exceeded in parts of drive train. Numerical methods used nowadays allow to predict parameters of vibrations generated simultaneously by all harmonics at any moment of engine run. Examples of such considerations will be presented in the next chapter.

\section{PARAMETERS OF ENGINE TO POWER RECEIVER COUPLING}

Moment of force and instantaneous speed are the principal parameters of engine to power receiver coupling. On a real object these parameters vary independently of any rules. Hence, classic method of determination of natural frequencies produced by a specific harmonics does not allow to define the probability of exceeding permissible parameters with satisfying accuracy. The process of vibrations develops in time and only determination of real parameters of the phenomenon in sufficiently long time secures unfailing transmission of the torque to a power receiverTherefore exists a need for definition of torque and instantaneous rotational speed in order to predict possible problems in the drive train. Definition of parameters of drive transmission using the numerical methods seems to be a simple task. Fig. 1 presents a schematic of drive train from IC engine to power receiver.

The mass moments of drive train elements inertia are marked as $\Theta$, the reduced length of elastic elements connecting inertial elements $-\mathrm{L}$ while the dumping between inertia elements $-\mathrm{C}$. The key elements of drive train are:

- crankshaft of the $\Theta_{1}, \mathrm{~L}_{12}$ and $\mathrm{C}_{12}$, i.e. reduced moment, reduced length and damping, respectively,

- flywheel of inertia moment $\Theta_{2}$ - stiffly coupled to the crankshaft, reduced length $\mathrm{L}_{12}$ and dumping $\mathrm{C}_{12}$, and transmitting the torque to an additional flywheel of the $\Theta_{3}$ inertia moment, and so on.

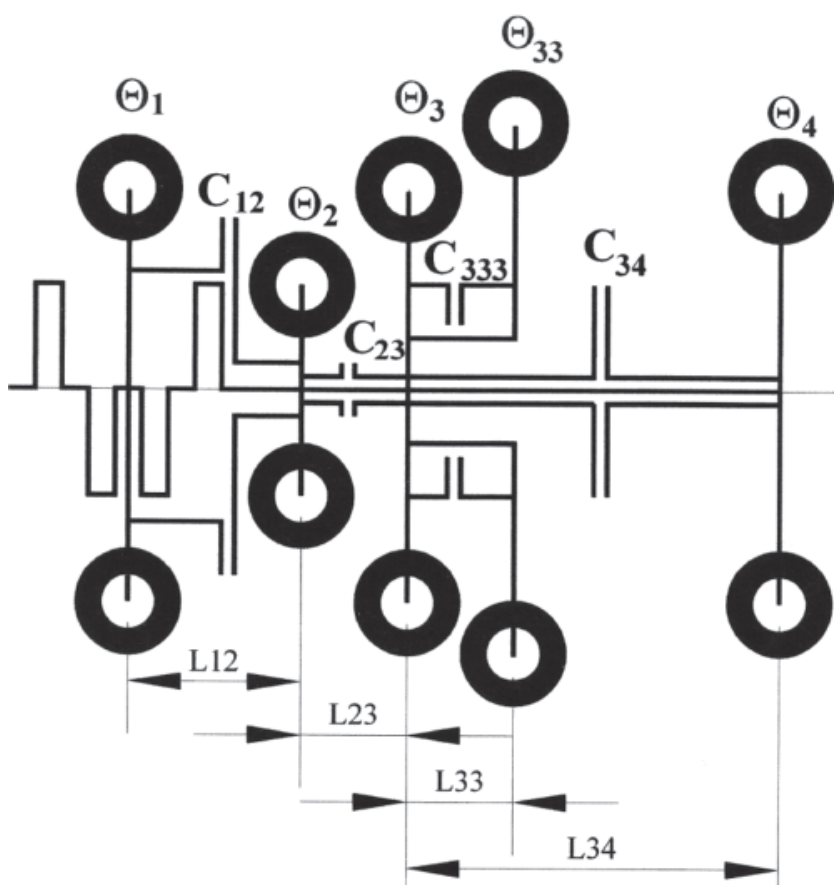

Fig. 3. Schematic of torque transmission from combustion engine to power receiver

The interrelations facilitating determination of coupling torque and momentary speed of drive train elements with an assumed time step delt are presented in procedure 1 [3].

In procedure 1:

- variable $b[j, i]$ is the coordinate of individual mass revolution angle,

- variable $e[j]$ is the yield resulting from shaft length $\mathrm{L}$ - see Fig. 3,

- variable tet $[j]$ is the mass moment of inertia $\Theta_{j}$,

- tlumj-dumping $\mathrm{Cj}, \mathrm{j}+1$,

- whereas the sign of deltmo moment decides if moment is transmitted to the electrical motor which happens during stroke of expansion, or it is transmitted to the combustion engine, when auxiliary strokes are performed.

Other terms of the procedure are not important to understand the method of correction of the power transmission shaft instantaneous speed.

\section{CONCEPT OF VIBRATION LIMITATION USING THE HYBRID ARRANGEMENTS}

Using the procedure 1 graphs of momentary angular speed of power train parts have been prepared which schematically are presented in Fig. 3. Corresponding results are presented in Fig. 4.

As it can be noticed, the quantity that varies most intensively is the shaft angular speed of the engine represented by the $\Theta_{1}$ mass inertia moment in Fig. 3.

The concept of vibration limitation on hybrid arrangements consists in assumption that the rotor of electrical machine plays the role of a flywheel of the $\Theta 2$ inertia moment. On such a system, presented schematically in Fig. 5, it is possible to extort a torque impulse from the electrical machine that could prevent the variability of its rotor angular speed.

Modern solutions of electric machine control allow to generate electric impulses affecting torque according to a given concept within a certain range. A number of ways have been investigated how to prevent the changes in rotational speed of electric machine rotor. Definitely the most effective way is to 


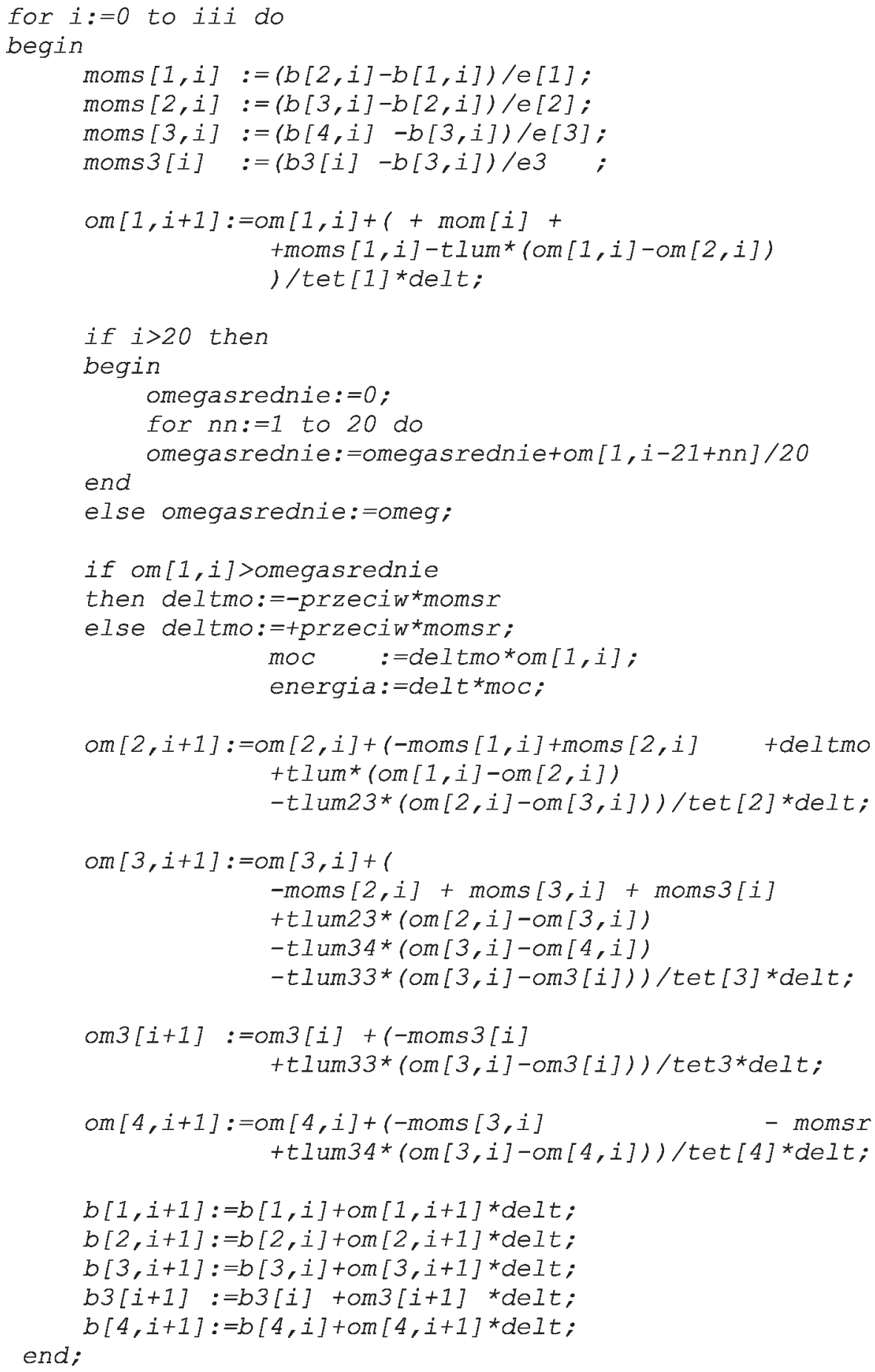

generate a torque proportional to rotor angular acceleration. So the problem is being reduced to the generation by the electric machine a torque counteractive to the engine torque.Alas, it is impossible by electric motor to generate a counteractive torque on the present stage of electric machine control.There are two reasons of such situation. Firstly generation of torque maximal over engine operation cycle would require an electric motor of mass exceeding many times the mass of combustion engine. Seondly, it is impossible to react imediately to the changing engine speed.

Therefore it has been decided to af fect the angular speed by the electric motor in a simple way consisting in:

- generation of negative torque equal to the engine average torque when rotor speed is higher than average speed, generation of positive torque of the same absolute value over the remaining period.

The effect of such operation can be evaluated when comparing graphs presented in Figs. 4 and 6.

Disregarding the technical possibilities of so precise reaction of electric motor to changing rotor speed, the correction of engine speed fluctuations using hybrid systems are explicitly limited. The carried out calculation of the real level of speed irregularity $\delta$ proves that correction gives over double improvement of $\delta$ factor . Above all such operation gives the reduction of engine generated noise. Obviously , the maximum values of coupling torque in individual parts of drive train reduce themselves as well. The values of 


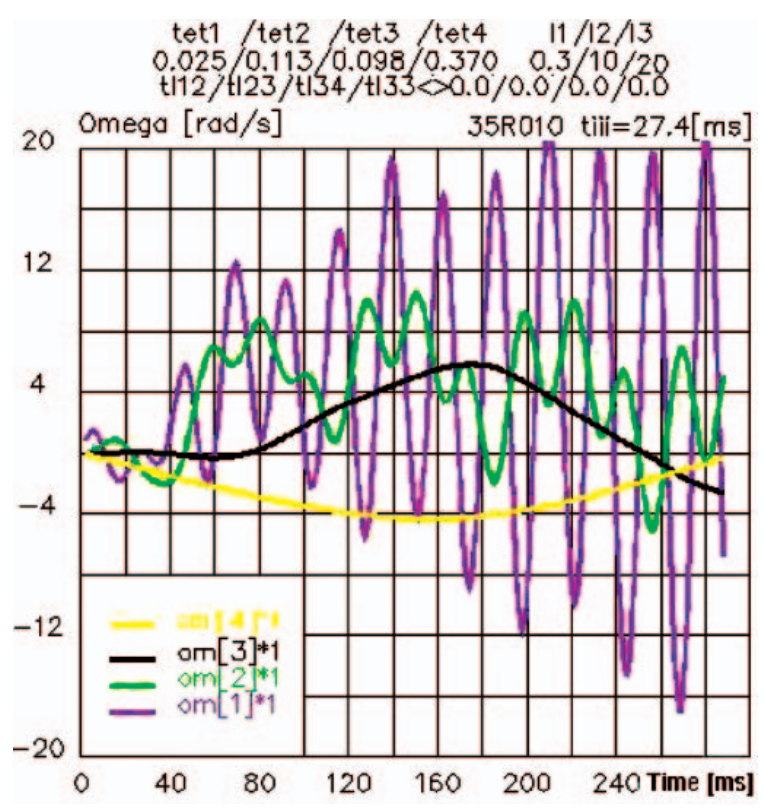

Fig. 4. Change in angular speed of drive train individual parts; description in text

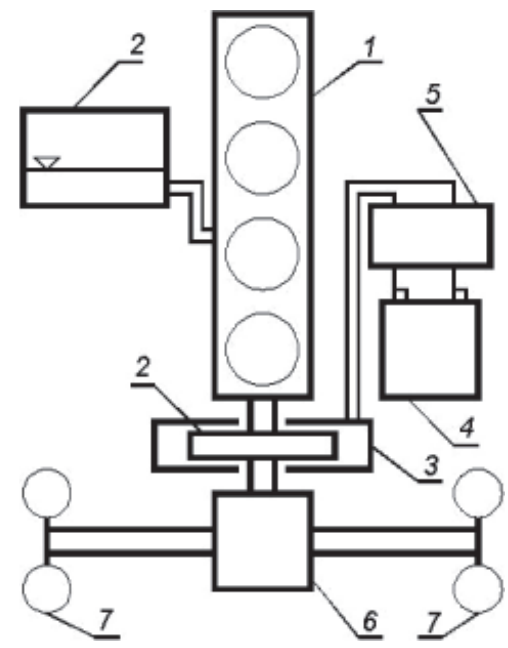

Fig. 5. Schematic of car hybrid drive: 1 -combustion engine, 2-fuel tank, 3 -electric machine operating as motor or generator, 4 -accumulator of electric energy, 5 - electric machine and electric energy accumulator coupling control, 6 -differential, 7 - wheels

tet1/tet2/tet3/tet4 11/12/13 $0.025 / 0.113 / 0.098 / 0.370 \quad 0.3 / 10 / 20$ $\mathrm{t} 112 / \mathrm{tl} 23 / \mathrm{tl} 34 / \mathrm{tl} 33<0.0 / 0.0 / 0.0 / 0.0$ $35 \mathrm{R} 011$ tiii $=27.4[\mathrm{~ms}]$

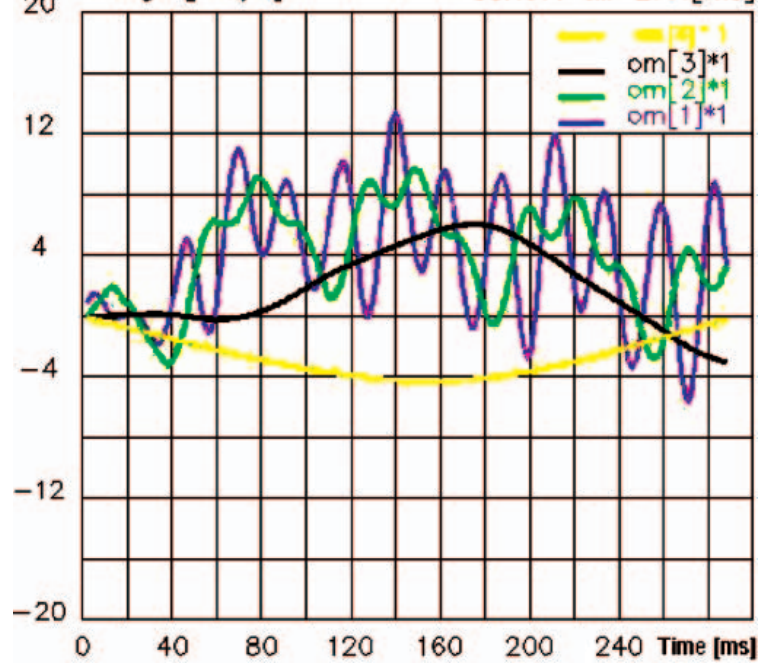

Fig. 6. Change in angular speed of drive train individual parts with speed correction performed by electric motor operating as a flywheel coupling torque on individual sections of drive train have been presented in Fig. 7 without correction and in Fig. 8 - with correction.

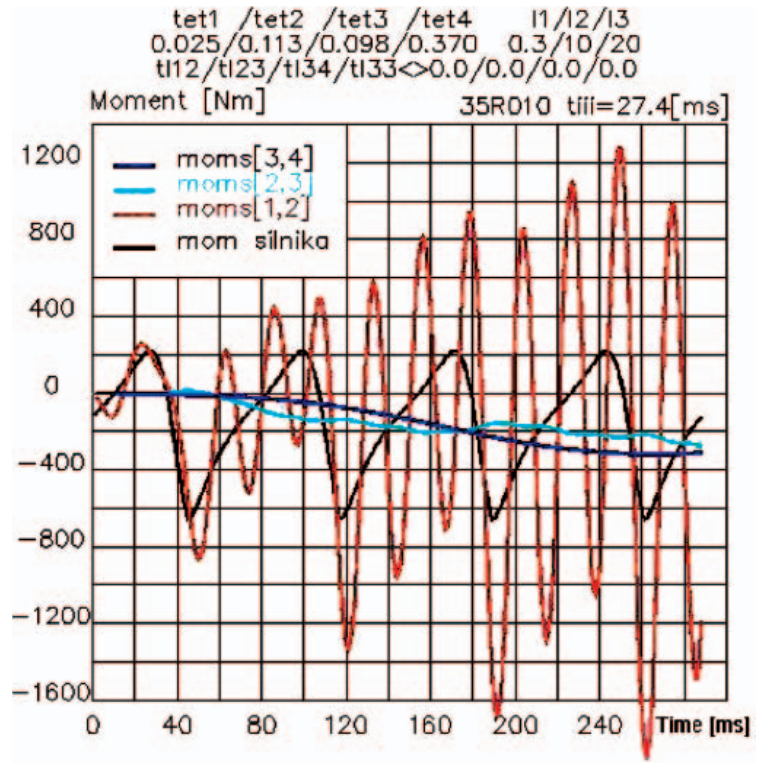

Fig. 7. Course of coupling torque between individual parts of drive train for example presented in Fig. 4

tet1 / tet2 /tet3/tet $4 \quad 11 / 12 / 13$ $0.025 / 0.113 / 0.098 / 0.370 \quad 0.3 / 10 / 20$ $\mathrm{t} 112 / \mathrm{t} 123 / \mathrm{tl} 34 / \mathrm{t} 133<0.0 / 0.0 / 0.0 / 0.0$

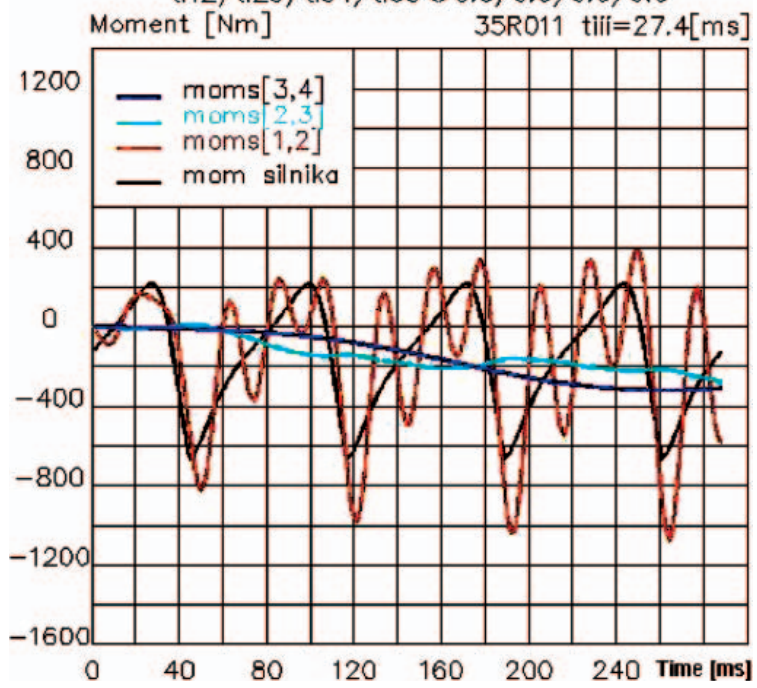

Fig. 8. Course of coupling torque between individual parts of drive train for example presented in Fig. 6

The presented considerations about the possibility of reduction the torsional vibrations in hybrid systems relate to the specific parameters of engine operation. As the additional analyses prove, the ef fect of vibration reduction not always is so spectacular as those presented in Figs. 4 and 6 to 8. The presented example relates to the case of resonance of the highest form (number 3 in this case) and 3 vibrations go to one cycle of engine operation. Lower form vibrations are dumped less. However, lower form of natural vibrations, especially the first form usually happens below the engine idle run speed, so it does not cause negative efects within the range of engine run.

\section{SUMMARY}

The problem of torsional vibrations in drives incorporating reciprocating engines is still considered as difficult for satisfactory solution. In particularly on direct injection diesels 
what is now a rule, double or even triple inertia flywheels are used in order to reduce torsional vibrations and accompanying noise. In extreme cases the use of viscous dampers becomes indispensable. All these solutions contribute to an increase in engine manufacturing costs, increase its weight while the use of viscous damper leads to ener gy dissipation which results in elevated fuel consumption. As it turns out by the ef forts on application of hybrid drives to car drive trains a chance emerges to limit vibrations and noise by the use of hybrid drives primarily provided for ecologically justified coupled combustion and electric drive. The solution proposed in present study creates a chance to make use of instantaneous ener gy surplus in two aspects:

- energy of car braking is accumulated for its use during acceleration when further ride is possible

- energy relative to the increasing shaft momentary speed during expansion stroke of combustion engine is accumulated for stabilization of rotational speed during auxiliary strokes.

\section{BIBLIOGRAPHY}

1. Braess HH, Seiffert U.: Vieweg Handbuch Kraftfahrzeugtechnik. Friedr. Vieweg \& Sohn Verlag, Wiesbaden 2003

2. A. Iskra.: Uwarunkowania techniczne stosowania paliw odnawialnych do napędu samochodów. V Międzynarodowe Sympozjum „Polacy Razem” - Energia odnawialna w kontekscie ochrony Środowiska", Verein Polnischer Ingenieurinnen und Ingenieure in Österreich, Wien 1618.11.2006

3. A. Iskra.: Transformacja wyników pomiaru momentu sprzęajacego silnik z odbiornikiem mocy do momentu rzeczywistego. Transformation of the Engine-to-receiver Coupling Torque Measurement Results to the Actual Value of Torque. Pomiary Automatyka Kontrola. 5/2006. Str. 41-45.

\section{CONTACT WITH THE AUTHOR}

Antoni Iskra, Prof.

Faculty of Mechanical Engineering and Management Poznan University of Technology Piotrowo 3 60-965 Poznan, POLAND e-mail: antoni.iskra@put.poznan.pl 